\title{
Evaluation of the impact of lopinavir/ritonavir (LPV/r) and ritonavir (RTV) on PR interval: results from a thorough QT study
} BA Da Silva*, J Li, YL Lin, PA Noertersheuser, WM Awni, CE Klein, TT Doan
and B Bernstein

Address: Abbott, Abbott Park, USA

* Corresponding author

from Ninth International Congress on Drug Therapy in HIV Infection

Glasgow, UK. 9-13 November 2008

Published: 10 November 2008

Journal of the International AIDS Society 2008, I I (SuppI I):PI0I doi:I0.I I86/I758-2652-II-SI-PI0I

This abstract is available from: http://www.jiasociety.org/content/II/SI/PI0I

(c) 2008 Da Silva et al; licensee BioMed Central Ltd.

\section{Purpose of the study}

PR prolongation has been reported with HIV protease inhibitors such as atazanavir. We evaluated the potential for PR prolongation with LPV/r and RTV.

\section{Methods}

Phase I, multiple-dose, open-label, placebo-controlled, randomized study conducted according to a crossover design. Study drugs were dosed for 3 days to allow for maximal exposure, as RTV-mediated CYP3A4 inhibition is complete and induction is minimal. $\mathrm{LPV} / \mathrm{r}$ was dosed at 400/100 mg BID and at supratherapeutic 800/200 mg BID. RTV was dosed at $400 \mathrm{mg}$ BID. Digital EKGs and pharmacokinetic samples were obtained on study Day 3. Absolute PR interval on Day 3 and change from baseline were evaluated. Exposure-PR response modeling was performed.

\section{Summary of results}

Substantially higher LPV (30-50\% for 400/100 mg BID and 3-fold for 800/200 mg BID) and RTV (2-fold) concentrations were achieved on Study Day 3 compared to historical steady-state values of LPV/r 400/100 mg BID and RTV 600 mg BID. Mean PR changes from baseline ranged from 11.6-24.4 msec (LPV/r 400/100 mg BID), 22.0$31.2 \mathrm{msec}(\mathrm{LPV} / \mathrm{r} 800 / 200 \mathrm{mg}$ BID) and $11.0-24.0 \mathrm{msec}$ (RTV $400 \mathrm{mg}$ BID), all $\mathrm{p}<0.0001$ compared to placebo. No subject had a PR interval greater than $286 \mathrm{msec}$. No subject experienced 2nd or 3rd degree atrioventricular block.

\section{Conclusion}

Based on the exposure-response model, it is estimated that the mean PR effect plateaus and has reached its maximum with the supratherapeutic 800/200 mg BID dose. At steady state, $\mathrm{LPV} / \mathrm{r}$ is expected to produce clinically insignificant increases in PR interval of 18 to $20 \mathrm{msec}$ and low dose ritonavir (100-400 $\mathrm{mg}$ daily) is expected to prolong PR by 4.8 to11.6 msec. LPV/r and RTV do not result in clinically significant increases in PR interval. However, this effect should be considered when co-administering $\mathrm{LPV} / \mathrm{r}$ or RTV with other drugs known to prolong PR interval or in patients with co-morbid conditions. 